\title{
Shaking table test and numerical simulation of 3D steel frame system
}

\author{
N. Avc1, F. Alemdar* \\ Yildiz Technical University, Department of Civil Engineering, İstanbul, Turkey
}

\begin{abstract}
Physical properties such as displacement obtained by experimental methods in civil engineering structures and modal parameters contain important information about the current state of the structure. The determination of these parameters is usually done by the time history analysis of the data collected by acceleration, velocity and displacement. In order to determine the structure behavior under dynamic effects, a finite element analysis is often preferred. In this study, the effects of earthquake acceleration records applied in different ratios in the 3D steel frame system with semi-rigid joint are investigated. The analysis results reveal that the effect of semi-rigid connections on structural systems is significant. In the 3 storey steel frame with semi-rigid assembly, the effect of these connections on the system is presented numerically and visually. Comparison of the dynamic displacement of finite element model with experimental data has $\% 99$ achieved in good relation with visual inspection.
\end{abstract}

\section{Keywords}

Finite element analysis; Steel frame system; Semi rigid connection; Dynamic analysis; Shaking Table Experiment

Received: 02 March 2019; Accepted: 24 June 2019

ISSN: 2630-5763 (online) @ 2019 Golden Light Publishing ${ }^{\circledR}$ All rights reserved.

\section{Introduction}

Determining the behavior of structures and structural elements in the field of civil engineering under dynamic effects gives important information about the damages that may occur in the structures. With that purpose, various laboratory tests are carried out in order to determine the acceleration, velocity, displacement, natural frequency and mode shapes of the structure [1-3]. Especially when using large-scale specimens in shaking table experiments, it is desirable to determine the dynamic effect at as many points as possible. This is time consuming and expensive method. However, with numerical analysis, dynamic parameters can be calculated much faster and cost- free at many points of the model. There are a lot of studies in the literature which perform static and dynamic analysis with finite element (FE) method. Some of the studies are summarized below.

Shaking table tests for a one-bay, two-story steel frame under simulated earthquake loading. The experiment aims to explain the inelastic behavior of steel frames subjected to earthquake load and to verify the validity of second-order inelastic dynamic analysis techniques of steel frames. A comparison of the results obtained from experiment and numerical analysis using beam element model was used [4].

Ghafoor [5] studied three-dimensional finite element models of some buildings using ANSYS program. The 3-D FE model of the shaking table at

\footnotetext{
Corresponding author

E-mail: falemdar@yildiz.edu.tr
} 
YTU Structure Laboratory was also created and placed under the models of the buildings. The FE models analyzed under various dynamic loads including harmonic and earthquake loads. The displacements of the substructures and superstructures at different points are obtained and the acceleration, total strength and the drifts of the buildings were determined.

Zhang and Li [6] evaluated a 1/5 scale threestorey reinforced concrete frame wall model on the shaking table. The test results were used to verify the accuracy of nonlinear dynamic analyses. The beams and columns of the model were simulated by the proposed fiber bundle element whereas the shear wall was simulated by the shell element. The results showed that the tested and calculated dynamic behavior and damage features were appropriate.

Nyugen and Kim [7] presented a simple effective numerical procedure based on the beamcolumn method for nonlinear elastic dynamic analysis of three-dimensional semi-rigid steel frames. The geometric nonlinearity is considered by using stability functions and geometric stiffness matrix. An independent zero-length connection element comprising six translational and rotational springs is used to simulate the steel beam-tocolumn connection. The dynamic behavior of rotational springs is captured through the independent hardening model. The Newmark numerical integration method combined with the Newton-Raphson iterative algorithm is adopted to solve the nonlinear equations. The nonlinear elastic dynamic analysis results are compared with those of previous studies and commercial SAP2000 software to verify the accuracy and efficiency of the proposed analysis.

Krolo et al. [8] presented the nonlinear seismic analysis of a steel frame without diagonals. The real behavior of semi-rigid joints was taken into account through prior numerical simulation of the selected type of joint. The bending moment and rotation relationship was substituted with a trilinear approximation and incorporated in seismic analysis according to the nonlinear static N2 method. Absolute and relative frame displacements were determined, and the corresponding results were compared with results for the steel frame with absolutely rigid joints.

Silva et al. [9] evaluated the fundamentals for prediction of a more realistic behavior of frames with semi-rigid connections under dynamic loading. In the examination of the structural behavior, the effects of geometric nonlinearity and connection flexibility were considered. In the finite element context, the numerical methodology proposed in algorithmic form to obtain the nonlinear transient response of the structural system was presented.

\section{Method and material}

\subsection{Geometric and mechanical properties of steel frame}

A 3D steel frame system was constructed with $1 / 4$ scale in the laboratory as shown in Fig. 1. The distance between the centers of the two columns is $130 \mathrm{~cm}$ and the height between the floors is $75 \mathrm{~cm}$. The IPN 100 profile was selected for the design of the columns and beams of the steel frame. L40x40x4 profile was used for the joints. In addition, two M12 bolts in both directions of the profile were applied with $1450 \mathrm{Nm}$ torque by the air wrench (Gav 2212) tool. In the strong axis of the frame, the girder-column connection is a semi-rigid joint, while the weak axis, column-beam joints are pin. The column-column connection was designed with $4 \mathrm{~mm}$ plate and eight M12-8.8 bolts. Material S235 steel was chosen and nonlinear material properties given in Fig. 2 were defined [10]. Each floor has a static load of $750 \mathrm{~kg}$ on wooden planks running in one direction and approximately 225 pieces of paving stones each having dimensions of 20x10x10 are placed. The frame connected with each column to the table with 4 M20 bolts and plate which has a thickness of $30 \mathrm{~mm}$. Plates connected column with surrounded weld which has thickness about $5 \mathrm{~mm}$. 

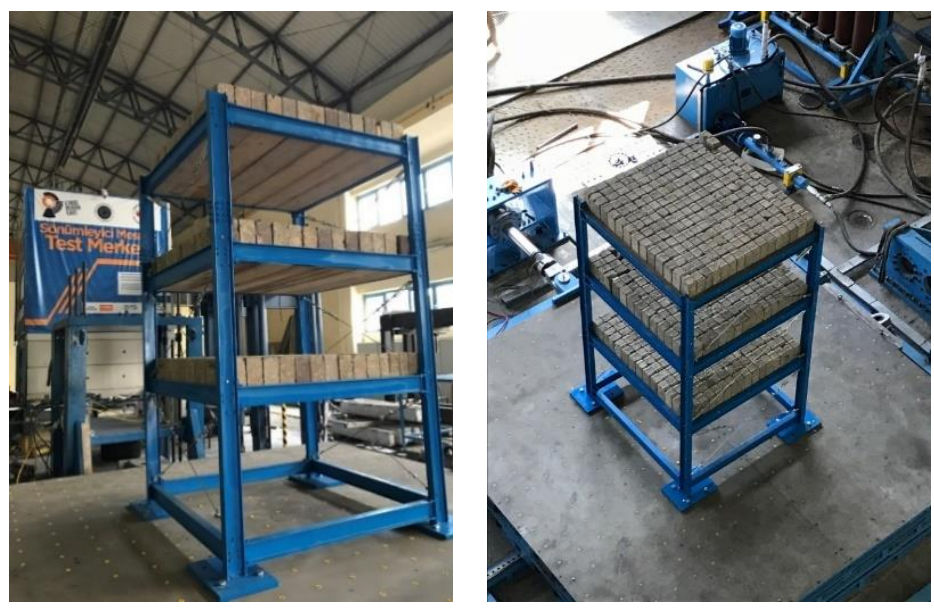

Fig. 1. Steel frame system

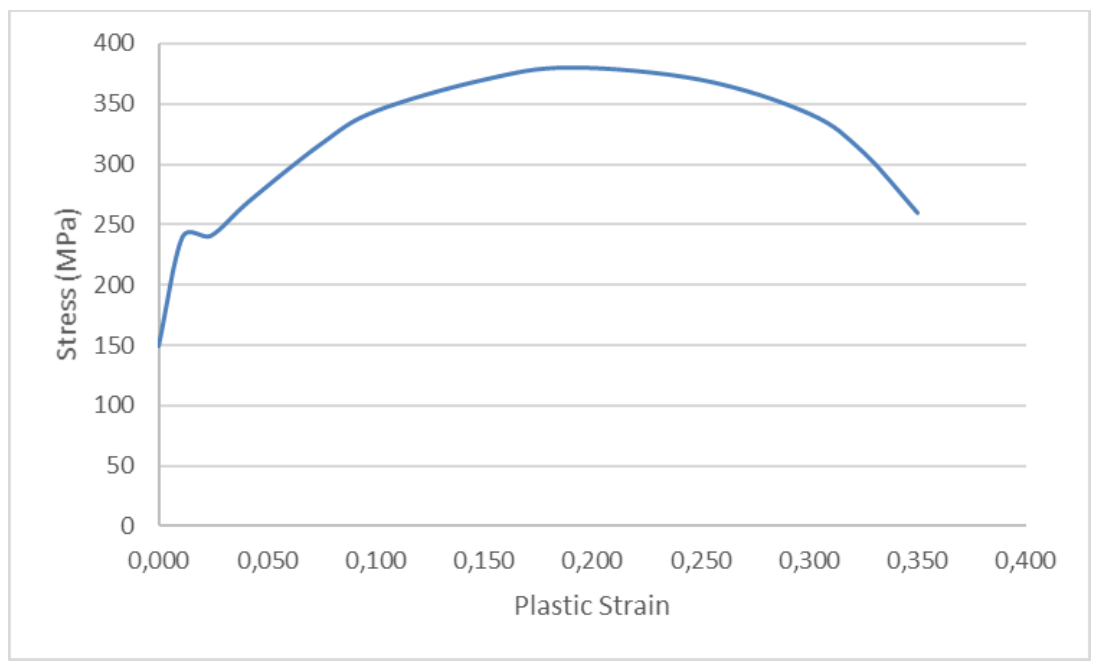

Fig. 2. Stress-strain relationship for steel (Nonlinear material)

\subsection{Finite element analysis}

The finite element (FE) model of the 3D steel frame test specimen was defined using ABAQUS [11] commercial program. The frame system is modeled as shown in Fig. 3.

The outer surfaces of the L40x $40 \mathrm{x} 4$ profile arms in the joints are divided into two equal areas. The end portions of the outer surfaces were selected with tie constraint, while the other parts were frictionless (Fig. 4). In addition, hard contacts were used to simulate the properties of a normal contact. Interaction between the beam and column connection was modeled using surface-to-surface contact as a frictionless.

The system mesh assignment is specially partitioned in the junction regions where necessary, so as not to cause irregularity. The model was meshed with C3D8T field-variable-dependent conductivity elements with eight nodes per element and three degrees of freedom per node. The mesh was refined near the connection as shown in Fig. 5. Reduced integration caused by the elements was utilized for the calculations.

The gravity loads (self-weight and applied loads) are first applied to the model. The static load 
of the paving stone was applied as non-structural mass. Northridge earthquake acceleration records with $\% 50$ and $\% 100$ scale are applied as dynamic loads under the shaking table as shown in Fig 6. Dynamic parameters were obtained using implicit analysis.

\subsection{Analysis results}

The effect of rotation in the semi-rigid joints of the frame system is investigated during the analysis.

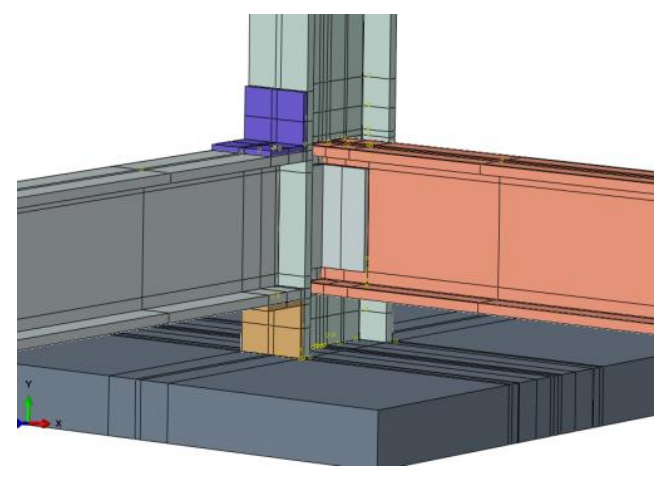

When the results of the analysis are examined, it is seen that the stress increases in the joint regions as shown in Fig. 7. The resultant of the maximum stress at the node increases the rotation effect in the joints. Rotation in semi-rigid joints was observed as the most important factor affecting the structural behavior. In this case, it was observed as an effect increasing the intensity of acceleration in the structure as shown in Fig. 8.

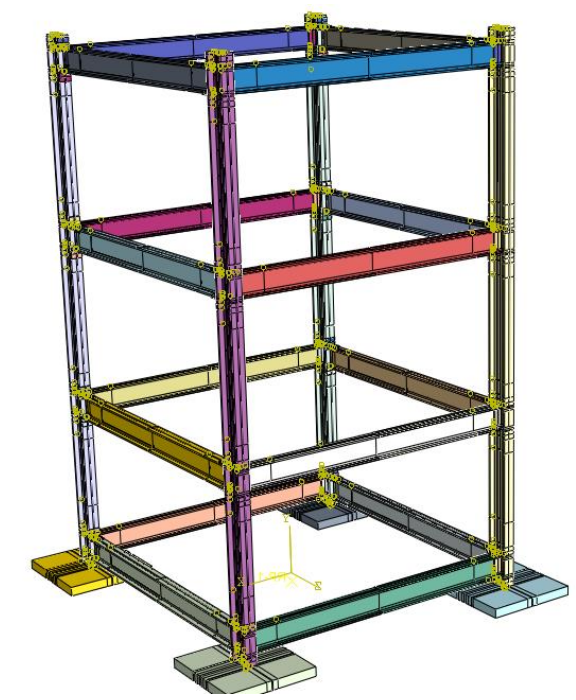

Fig. 3. FE model of the steel frame system
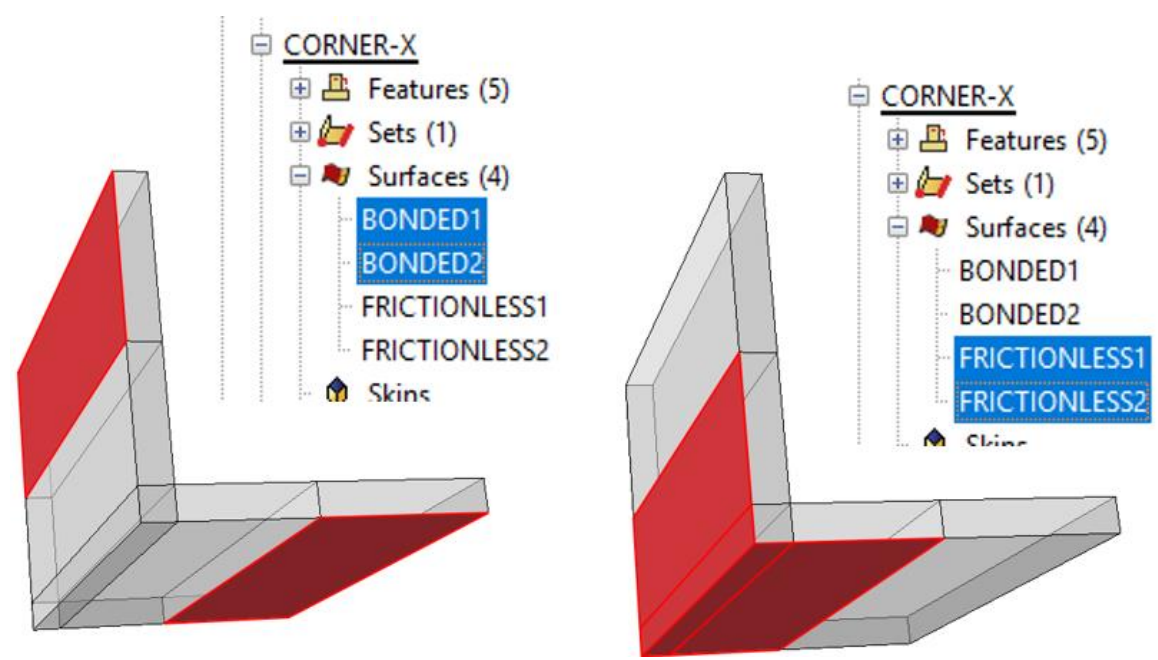

Fig. 4. Connection Detail 


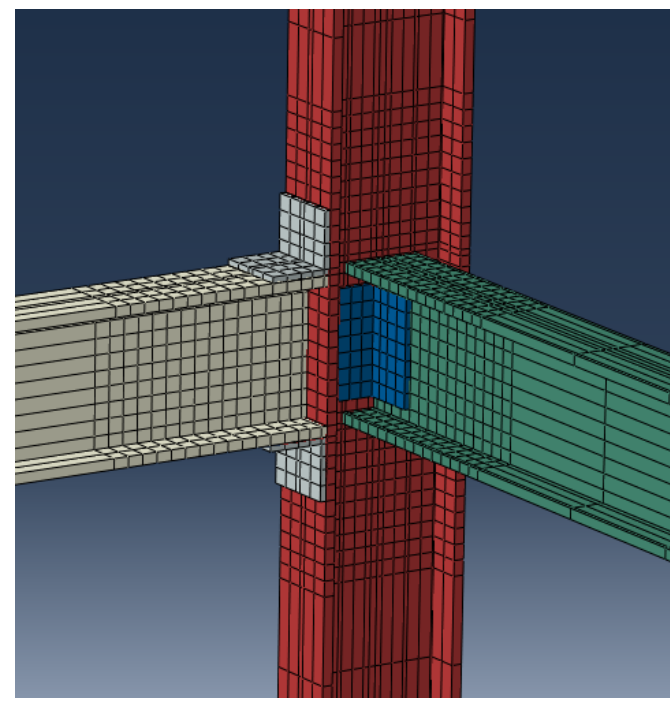

Fig. 5. Mesh of steel frame system
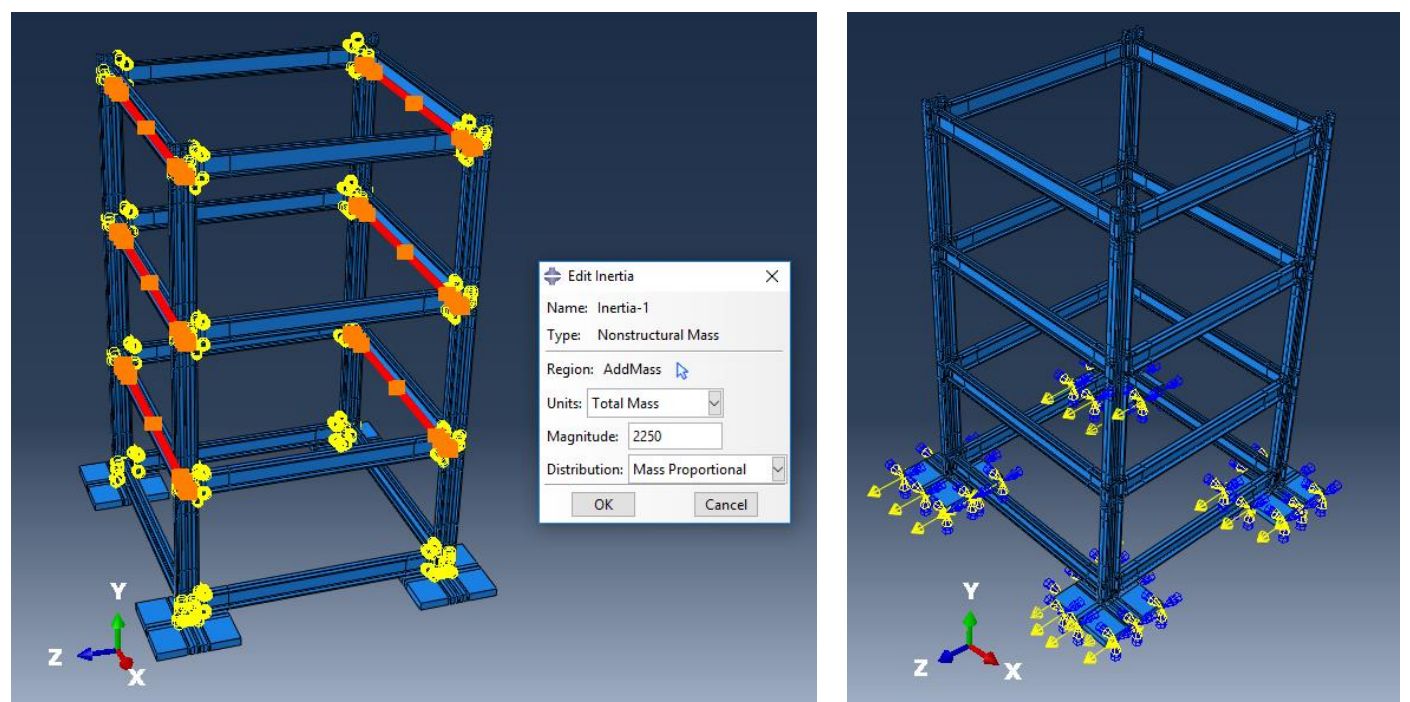

Fig. 6. Static and dynamic load of structure

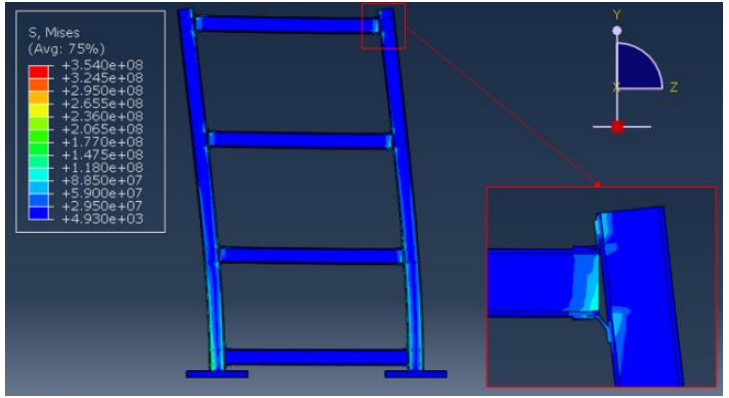

a)

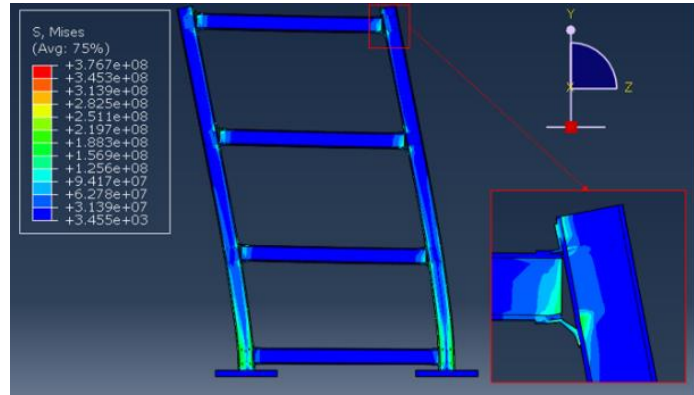

b)

Fig. 7. Von mises stress (Deformation Scale Factor $=10$ ) under 50\% (a) and 100\% (b) Northridge earthquake record 


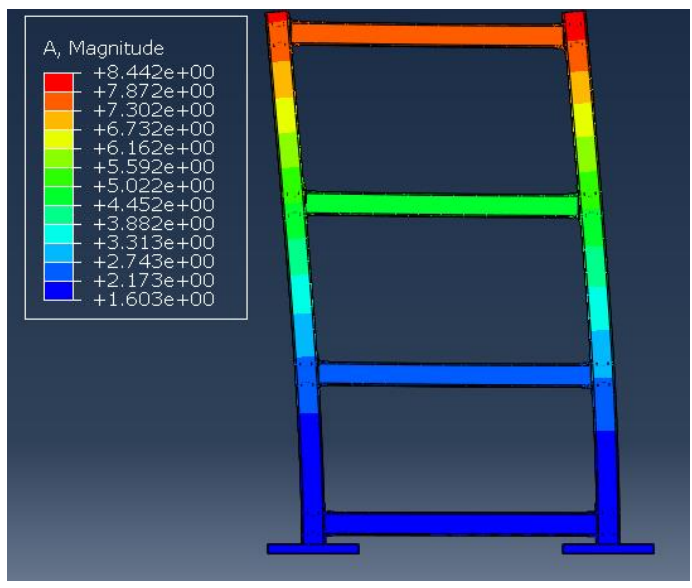

a)

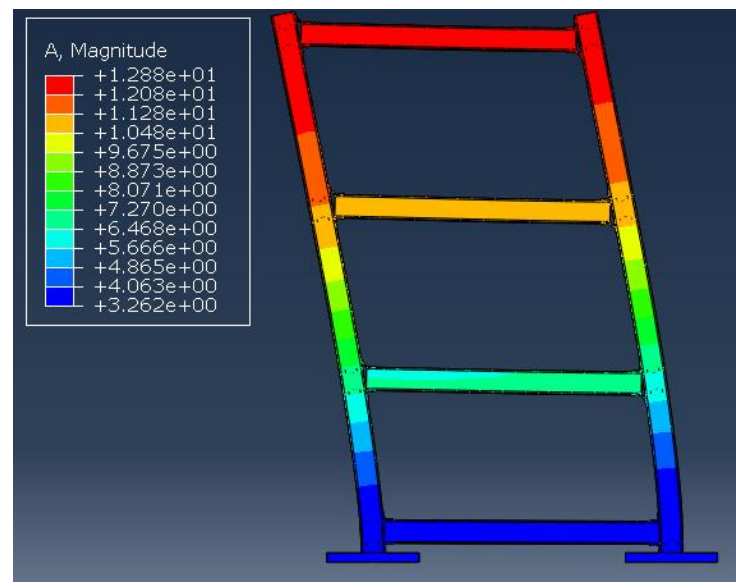

b)

Fig. 8. Acceleration value of system under 50\% (a) and $100 \%$ (b) Northridge earthquake record

In $100 \%$ Northridge earthquake acceleration record, relative displacement effect and second order effects are observed more than the 50\% Northridge earthquake acceleration record. When $\% 50$ scale Northridge earthquake acceleration was applied, the maximum base shear force in the system reached up to $18 \mathrm{kN}$, while the displacement between the base and the top point reached $2.28 \mathrm{~cm}$. In the application of $\% 100$ scale Northridge earthquake acceleration, the maximum base shear force in the system raised up to $27 \mathrm{kN}$, whereas the displacement between the base and the top point reached $3.88 \mathrm{~cm}$. In addition, plasticity was observed in the connection regions under $\% 100$ scale Northridge earthquake record as seen in Fig. 9.

\subsection{Comparison of the displacement results}

The horizontal top displacement data obtained from the Abaqus model and the shaking table experiment for the two applied records were compared to verify the FE model. Fig. 10 and the Fig. 11 show the comparisons as the $\% 50$ and $\% 100$ scale Northridge records are applied, respectively. It is seen that good relation was found when two data were compared.

\section{Conclusions}

The shaking table tests was performed with $50 \%$ and $100 \%$ scaled Northridge earthquake acceleration records. A 3D FE model of the steel frame system was carried out in the Abaqus program as close as possible to the actual model. The displacement results at the top of the model were obtained by shaking table tests and the FE model analysis. The results give suitable data for the verification.

In 3 storey steel frame with semi-rigid assembly, the effect of these connection types on the system is presented numerically and visually. In semi-rigid joints, stress concentrations were observed in the joints rather than the elements. It is clearly distinguished from this study that semi-rigid beam-to-column and column-to foundation connections are very efficient on general structural behavior. The connection behavior has a strong influence on the results. As the earthquake acceleration values increased, second order effects were more clearly revealed. The importance of the design of connection regions is emphasized in the design of the earthquake resistant structure.

Although a very standard camera was used to record the shaking tests, the displacement results show very close data with the expensive instrumentation. It can be an economical way to get the results. 


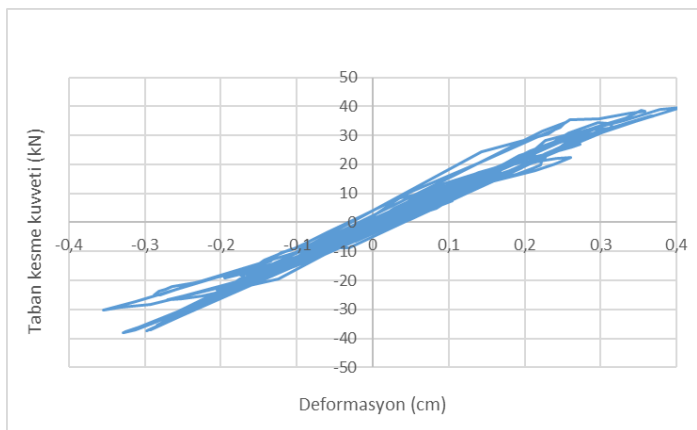

a)

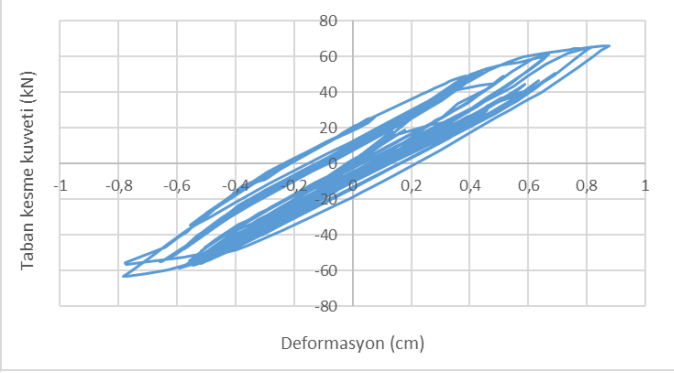

b)

Fig. 9. Base Shear-Displacement curves under 50\% (a) and 100\% (b) Northridge earthquake

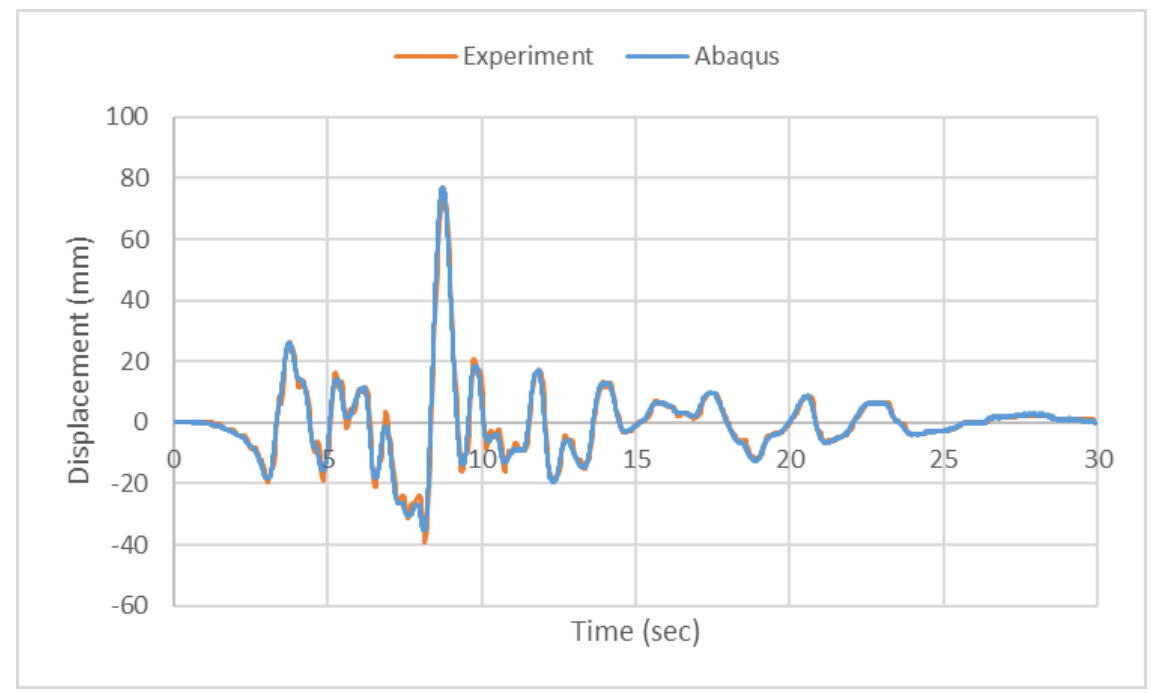

Fig. 10. Comparison of the top floor horizontal displacement (\%50 scale)

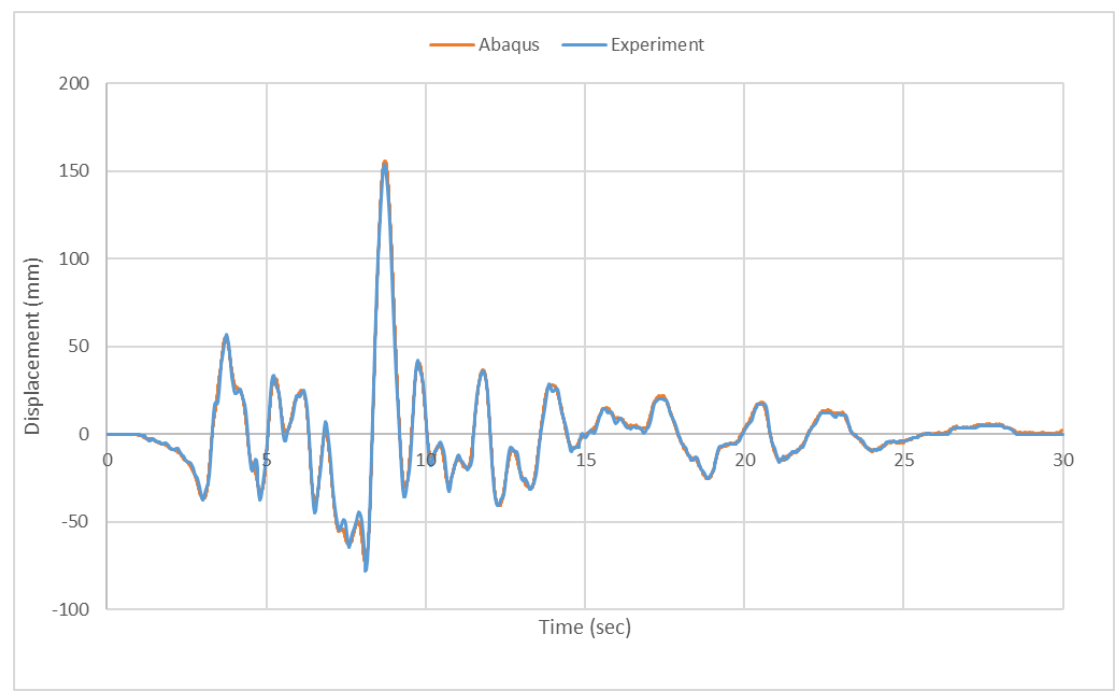

Fig. 1. Comparison of the top floor horizontal displacement (\%100 scale) 
The FE model under the $\% 50$ Northridge earthquake shows elastic behavior and thus no plastic deformation was occurred in the testing. However; in the \%100 scaled earthquake testing, there is plastic gap in the connection region. It can be said that the gap was around $2 \mathrm{~mm}$. These plastic deformations were at the first floor level and on the top flange of the beam. It also observed in the FE model of the frame.

\section{References}

[1] Iwashita K, Kimura H, Kasuga Y, Suzuki N (2002) Shaking table test of a steel frame allowing uplift. Journal of Structural and Construction Engineering 561:47-54

[2] Midorikawa M, Azuhata T, Ishihara T, Wada A (2006) Shaking table tests on seismic response of steel braced frames with column uplift. Earthquake Engineering Structures. 35:1767-1785.

[3] Li S, Zuo Z, Zhai C, Xu S, Xie L (2016) Shaking table test on the collapse process of a three-story reinforced concrete frame structure. Engineering Structures 118 (2016):156-166.

[4] Kim SE, Lee D-H, Ngo-Huu C (2007) Shaking table tests of a two-story unbraced steel frame. Journal of Constructional Steel Research 63 (2007):412-421.

[5] Ghafoor HMA. Numerical simulation for investigation dynamic behavior of buildings with a shaking table, MSc Thesis. Yildiz Technical University, 2018.

[6] Zhang H, Li HN. Shaking table test and dynamic response analysis of reinforced concrete structure. 15 WCEE Lisboa, Portugal 2012.

[7] Nguyen PC, Kim SE (2013) Nonlinear elastic dynamic of space steel frames with semi-rigid connections. International Journal Constructional Steel Research 84: 7281.

[8] Krolo P, Čaušević M, Bulić M. (2015) Nonlinear seismic analysis of steel frame with semi-rigid joints. Građevinar 67(6): 573-583.

[9] Silva ARD, Batelo EAP, Silveira RAM, Neves FA, Gonçalves PB (2018) On the nonlinear transient analysis of planar steel frames with semi-rigid connections: from fundamentals to algorithms and numerical studies. Latin American Journal of Solids and Structures, 15(3), e28.

[10] Salmon C, Johnson J. Steel Structures Design and Behavior, Harper and Row Publishers, New York, 1980.
[11] ABAQUS/Explicit (Version 6.14), User's manual, Finite Element Software. Available from: http://www.simulia. com. 